\title{
Effect of chemical and radiofrequency plasma treatment on photoluminescence of $\mathrm{SiO}_{\mathrm{x}}$ films
}

\author{
I.Z. Indutnyy, V.S. Lysenko, I.Yu. Maidanchuk, V.I. Min'ko, A.N. Nazarov, A.S. Tkachenko, \\ P.E. Shepeliavyi, V.A. Dan'ko \\ V. Lashkaryov Institute of Semiconductor Physics, NAS of Ukraine, \\ 41, prospect Nauky, 03028 Kyiv, Ukraine \\ E-mail: indutnyy@isp.kiev.ua
}

\begin{abstract}
Effect of hydrogen radiofrequency plasma and chemical treatment on photoluminescence (PL) spectra of $\mathrm{SiO}_{x}$ layers containing $\mathrm{Si}$ nanoparticles are investigated. Considerable PL intensity growth in the samples containing Si nanocrystals $\left(\mathrm{nc}-\mathrm{Si}-\mathrm{SiO}_{\mathrm{x}}\right.$ ) after plasma treatment is observed. The process saturates for time of 15 minutes. Chemical treatment in ammonia and acetone vapour before thermal annealing of $\mathrm{SiO}_{\mathrm{x}}$ layers leads to the considerable changes in PL spectra effecting both on the band shape and on the intensity. The possibility of controlled changes in PL spectra in nc-Si$\mathrm{SiO}_{2}$ layers is shown.
\end{abstract}

Keywords: nanocrystals, silicon oxide, photoluminescence, thin film.

Manuscript received 07.10.05; accepted for publication 15.12.05.

\section{Introduction}

Since the discovery of visible light emission from porous silicon and silicon nanocrystals (nc-Si), the number of investigations on $\mathrm{SiO}_{\mathrm{x}}$ thin films containing silicone nanoinclusions [1-3] has increased, because of its promising applications in Si-based optoelectronics. Photoluminescence (PL) observed in such structures in visible and near infrared range is connected with quantum-confinement effect of silicon nanoclusters in $\mathrm{SiO}_{\mathrm{x}}$ films annealed at high temperatures.

Several techniques are used to fabricate silicon suboxide films, namely: chemical vapor deposition, ion implantation, laser ablation, magnetron sputtering, thermal evaporation in vacuum and others. All these methods allow to fabricate amorphous $\mathrm{SiO}_{\mathrm{x}}$ films with required $x$. Formation of $\mathrm{nc}-\mathrm{Si}$ is thermostimulated process that is often described by reaction:

$y \mathrm{SiO}_{\mathrm{x}} \rightarrow x \mathrm{SiO}_{\mathrm{y}}+(y-x) \mathrm{Si}$,

where $y>x$. The annealing temperature determines the structure of inclusions: annealing at 500 to $900{ }^{\circ} \mathrm{C}$ favors coagulation of $\mathrm{Si}$ atoms into amorphous clusters, at higher temperatures nanocrystalline $\mathrm{Si}$ particles are formed $[1,2]$.

To provide controlled emission in $\mathrm{nc}-\mathrm{Si}-\mathrm{SiO}_{\mathrm{x}}$ layers, it is necessary to study factors that influence on PL spectra. Although the mechanism of light emission in such structures is still under discussion, it is known that emission energy depends on the nanoparticle size. As for control of the size and volume density of $\mathrm{Si}$ nanoinclusions, it seems to be useful to control the structure of deposited $\mathrm{SiO}_{x}$ layers by changing the conditions of their deposition. The size control in these systems is usually realised by varying the silicon content in $\mathrm{SiO}_{\mathrm{x}}$ layers [3], or by introducing a superlattice-like structure into the synthesis process [4]. Another method for size-controlled silicon nanocrystal synthesis, using oblique deposition and thermal annealing of $\mathrm{SiO}_{\mathrm{x}}$ layers, was proposed in our previous paper [5]. Thermal evaporation of silicon monoxide on the substrate obliquely oriented to the direction of the evaporated substance flow leads to the formation of the porous $\mathrm{SiO}_{\mathrm{x}}$ films with the columnar structure [6]. Depending on the angle of evaporation and other parameters of the technological process, the diameter of deposited columns varies from 10 to $30 \mathrm{~nm}$. Thermostimulated formation of $\mathrm{Si}$ nanoinclusions in such films takes place in a limited volume of $\mathrm{SiO}_{\mathrm{x}}$ columns, which can result in smaller dimensions of nc-Si than in continuous films with the same content $(x)$.

PL of deposited films depends also on the temperature, time and atmosphere of annealing. It was shown [7] that the choice of annealing environment during the formation of silicon nanocrystals in the oxide matrix may have a significant effect on their PL. Hydrogen and nitrogen treatment have a passivating 
effect on nonradiative defects at the nc-Si-oxide interface: annealing in forming gas $\left(5 \% \mathrm{H}_{2}\right.$ in $\left.\mathrm{N}_{2}\right)$ at $500{ }^{\circ} \mathrm{C}$ [7] leads to several times growth in PL intensity. Annealing of $\mathrm{SiO}_{\mathrm{x}}$ films in nitrogen atmosphere leads to slow growth in PL intensity up to 16 hours of its duration $[8,9]$.

A more effective method of defect annealing in the silicon structure is the low-pressure RF plasma treatment $[10,11]$. This paper presents the results of investigation of $\mathrm{PL}$ in $\mathrm{nc}-\mathrm{Si} / \mathrm{SiO}_{2}$ structures being passivated using hydrogen plasma and chemical treatments.

\section{Experiment}

Thin $\mathrm{SiO}_{\mathrm{x}}$ layers were obtained by thermal evaporation of $\mathrm{SiO}$ (Cerac Inc., purity of $99.9 \%$ ) in vacuum at the residual pressure of $1 \ldots 2 \times 10^{-3} \mathrm{~Pa}$. The angle $(\beta)$ between the vapor flow and the substrate normal was 0 and $75^{\circ}$ for different samples. Two-sided polished $\mathrm{Si}$ wafers and silica plates were used as the substrates. The substrate temperature during deposition was $150^{\circ} \mathrm{C}$.

The rate of deposition onto the normally oriented substrate was $1.5 \mathrm{~nm} / \mathrm{s}$ and decreased with increasing $\beta$. The time of deposition was chosen to provide the deposition of the same mass on the same area of the samples, independently on substrate orientation. Thickness of the films were monitored in situ by the quartz-crystal-oscillator monitor system (КИТ-1) and measured after deposition by a microinterferometer МИИ-4. Тhe thickness of normally deposited films was equal to 250-300 nm, for oblique deposited films - about $600 \mathrm{~nm}$. The density ( $\rho)$ of investigated samples was determined by comparing the thickness of the films deposited at different angles with the films deposited normally. The density of normally deposited film was measured early and was equal to $1.90 \mathrm{~g} / \mathrm{cm}^{3}$ [12].

Portions of obliquely deposited samples were exposured to acetone and ammonia saturated vapor atmosphere for 48 hours at the room temperature. After that, all the samples were annealed in vacuum $\left(10^{-3} \mathrm{~Pa}\right)$ at 700 and $950{ }^{\circ} \mathrm{C}$ to obtain amorphous and crystalline $\mathrm{Si}$ inclusions in the oxide matrix. Chemically non-treated films were passivated by the radiofrequency (RF) plasma treatment in hydrogen atmosphere $\left(20 \% \mathrm{H}_{2}\right.$ in $\mathrm{N}_{2}$ ), diode type reactor, frequency 13.6 MHz.

PL spectra were measured at room temperature using SPM2 monochromator with nitrogen-cooled ФЭУ-62 photomultiplier. The $488 \mathrm{~nm}$ line of an $\mathrm{Ar}^{+}$ laser was used for excitation.

\section{Results and discussions}

\subsection{RF plasma treatment}

Main characteristics of prepared samples are summarized in Table.

As it can be seen from Table, the density of films decrease greatly for oblique deposited samples, which is
Table. Characteristics of deposited films.

\begin{tabular}{|c|c|c|c|c|c|c|c|}
\hline \multirow{4}{*}{ 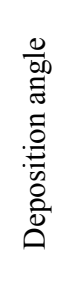 } & \multirow{4}{*}{ 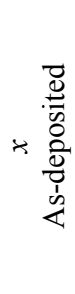 } & \multicolumn{2}{|c|}{$\begin{array}{c}y \\
\text { Annealed }\end{array}$} & \multirow{4}{*}{ 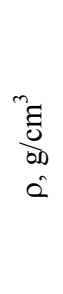 } & \multirow{2}{*}{\multicolumn{3}{|c|}{$\begin{array}{c}\text { Peak position } \\
\text { in the IR absorption band, } \\
\mathrm{cm}^{-1}\end{array}$}} \\
\hline & & \multirow{3}{*}{$\begin{array}{l}700 \\
{ }^{\circ} \mathrm{C}\end{array}$} & \multirow{3}{*}{$\begin{array}{l}950 \\
{ }^{\circ} \mathrm{C}\end{array}$} & & & & \\
\hline & & & & & & \multicolumn{2}{|c|}{$\begin{array}{c}\text { Annealed } \\
\text { sample }\end{array}$} \\
\hline & & & & & & $700^{\circ} \mathrm{C}$ & $950{ }^{\circ} \mathrm{C}$ \\
\hline 0 & 1.27 & 1.41 & 1.91 & 1.90 & 1023 & 1040 & 1073 \\
\hline $75^{\circ}$ & 1.51 & 1.60 & 1.92 & 0.88 & 1052 & 1063 & 1076 \\
\hline
\end{tabular}

the evidence of a porous structure of such layers (under annealing, the density does not practically change). The porosity of samples with the same mass of deposited $\mathrm{SiO}_{\mathrm{x}}$ on the same substrate area was determined as $(d(75)-d(0)) / d(75)$, where $d(75)$ is the thickness of film deposited at angle $75^{\circ}, \mathrm{d}(0)$ is the thickness of the normally deposited film, and porosity was equal to $52 \%$.

To estimate the oxide composition of both asdeposited ( $x$ ) and annealed ( $y$ ) samples, we used monotonous dependence [13] of the maximum position for the main IR absorption band for $\mathrm{SiO}_{\mathrm{x}}$ in the range $1000-1100 \mathrm{~cm}^{-1}$ (which corresponds to the asymmetric stretching vibration of the oxygen atom in its two-fold coordinated bridging bonding site) on the oxide composition.

The as-evaporated $\mathrm{SiO}_{\mathrm{x}}$ films show rather weak photoluminescence in the visible range. After annealing at $700-950{ }^{\circ} \mathrm{C}$, the intensive wide band appears in the near IR range with the peak position that depends on the deposition angle and temperature. Normalized PL spectra of normally and oblique deposited as well as annealed at $950{ }^{\circ} \mathrm{C}$ are given in Fig. 1. It can be seen that position of PL band for obliquely deposited film is

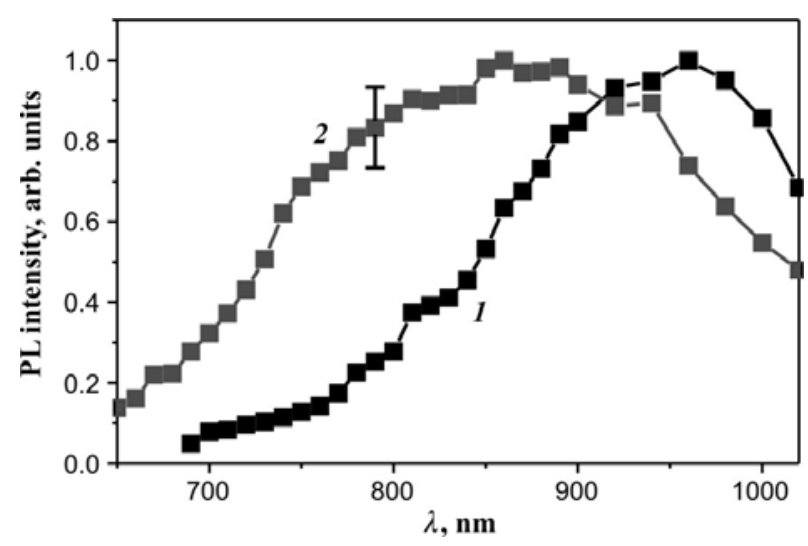

Fig 1. Normalized PL spectra of normally (1) and obliquely (2) deposited and annealed at $950{ }^{\circ} \mathrm{C} \mathrm{SiO}_{\mathrm{x}}$ films. 
blueshifted, and the maximum position is equal to $860 \mathrm{~nm}$, when for the normally deposited film it is about $960 \mathrm{~nm}$. This blue shift in PL spectra is explained by decreasing the nc-Si size that depends on the deposition angle and is the result of the porous (columnar) structure of the film [5]. In columns of small diameter (less than $10 \mathrm{~nm})$ at high-temperature annealing, the $\mathrm{Si}$ nanoparticles of smaller sizes are formed, in columns of greater diameter the size of particles is the same as in continuous $\mathrm{SiO}_{\mathrm{x}}$ films. With increasing the deposition angle, porosity of the deposited films is increased, and the average diameter of columns decreases. It enables to control the light-emitting characteristics of nc-Si- $\mathrm{SiO}_{x}$ structures by changing the deposition angle.

The normally and obliquely deposited and annealed films were treated with RF hydrogen plasma. No changes in PL spectra for samples annealed at $700^{\circ} \mathrm{C}$ were observed. As for the samples annealed at $950{ }^{\circ} \mathrm{C}$, this RF plasma treatment leads to significant growth of PL intensity (about 10 times) for both types of the samples. Fig. 2 shows the evolution of the roomtemperature PL spectra obtained for normally deposited samples annealed at $950^{\circ} \mathrm{C}$ after $5,10,15$ and $20 \mathrm{~min}$ plasma treatments. It can be seen (e.g., in the inset) that the intensity-time dependency is linear for times 5 to $15 \mathrm{~min}$, and for larger times it reaches saturation. Further treatments do not lead to enhancement of the PL intensity. The same results were obtained for obliquely deposited films.

The position of the PL peak doesn't change after this plasma treatment both for porous and solid samples.

Results obtained for plasma treatment can be interpreted as follows. There exist several factors capable to influence on treated samples $[10,11]$ : 1) low energy ion and electron bombarding; 2) X-ray and UV irradiation over a wide spectral range; 3) RF electromagnetic field; 4) thermal heating. Atoms and ions of hydrogen penetrate inside the $n c-S i-S i O_{x}$ film

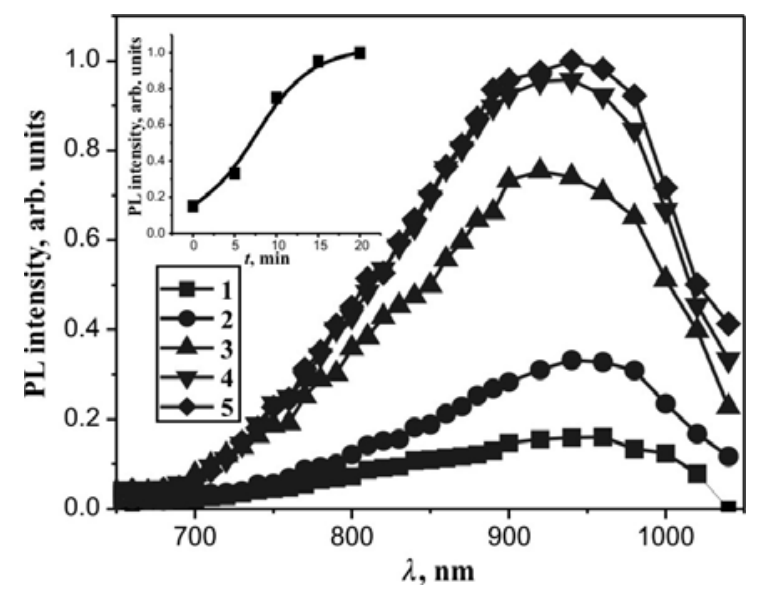

Fig 2. PL spectra of normally deposited samples annealed at $950{ }^{\circ} \mathrm{C}$ and treated with RF plasma for various times: nontreated (curve 1), treated for $5 \mathrm{~min}(2), 10$ (3), 15 (4), and 20 min (5). In inset: the dependency of the PL peak intensity on the time of a plasma treatment. causing the following changes: neutralization of fixed charges, relaxation of mechanical strains, annealing of defects and reduction of surface states at the $\mathrm{Si} / \mathrm{SiO}_{2}$ interface. In our opinion, the latter process is determinative in the growth of PL intensity. Most of authors recognised the critical role of $\mathrm{P}_{b}$ centres nonradiative centres at the $\mathrm{Si} / \mathrm{SiO}_{\mathrm{x}}$ interface. $\mathrm{P}_{b}$ centres are the dangling bonds of silicon that cause nonradiative quenching and can be passivated by hydrogen. It was shown using electron spin resonance (ESR) experiments that the PL intensity in these nc-Si-SiO ${ }_{x}$ films inversely correlates with the amount of $\mathrm{P}_{b}$ centers [7]. Consequently, annealing of the nc-Si-SiO ${ }_{x}$ samples in hydrogen environment (forming gas), or plasma treatment enhance the PL intensity due to a reduction in the $\mathrm{P}_{b}$ concentration, without modifying the spectral shape of the PL emission.

It should be noted that enhancement of the PL intensity in the case of treatment by plasma considerably exceeds influence of annealing in hydrogen atmosphere (in our experiments the maximal enhancement of intensity was 30 -fold). That is protons and atomic hydrogen, which penetrate in oxide during the plasma treatment, together with electric recharging the defect states cause considerably more effective annealing of the surface states on the nc-Si-SiO ${ }_{x}$ interface $[10,11]$ than the standard hydrogen annealing [7]. Plasma treatment not only passivates Si dangling bonds but also anneals structural defects in silicon and its oxide, that is orders structure of material.

As for samples annealed at $700{ }^{\circ} \mathrm{C}$ where growth of the PL intensity was not observed, it can be explained by the following assumption. Annealing of the $\mathrm{SiO}_{\mathrm{x}}$ films at lower temperatures leads to formation of silicon particles with an amorphous structure [1]. Passivation of such particles is not enough effective because of the absence of a sharp interface between silicon and the matrix. Moreover, the concentration of $\mathrm{P}_{b}$ centers in films

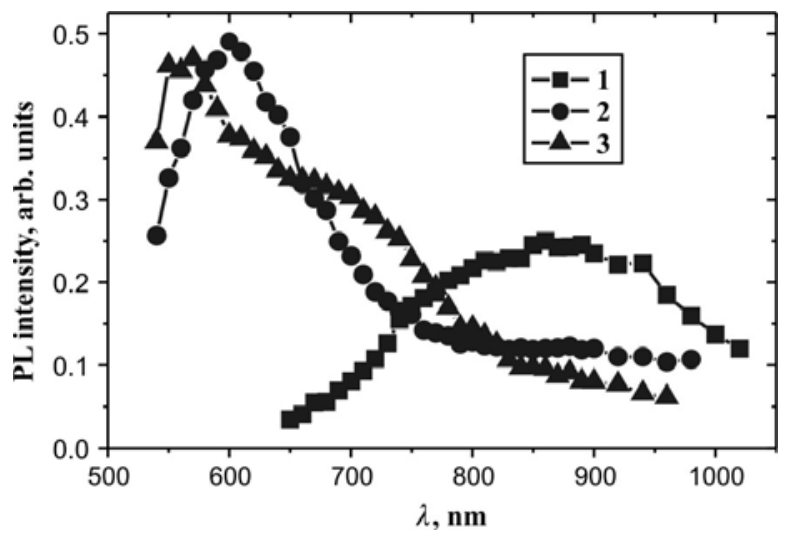

Fig. 3. PL spectra of obliquely deposited samples: non-treated (curve 1), exposured to acetone (2), ammonia (3) and annealed after the chemical treatment at $950{ }^{\circ} \mathrm{C}$. 
annealed at $200 \ldots 700^{\circ} \mathrm{C}$ decrease by more than one order of its magnitude relatively to the as-deposited film [4]. More high-temperature annealing induces a growth of the $\mathrm{P}_{b}$ center density. Therefore, in samples with amorphous $\mathrm{Si}$ nanoinclusions influence of $\mathrm{P}_{b}$ centers on PL will not be substantial because of their considerably smaller concentration, and passivation of these layers practically does not increase the PL intensity.

\subsection{Chemical treatment}

PL spectra of obliquely deposited samples non-treated (curve 1), exposured to acetone (2), ammonia (3) and annealed at $950{ }^{\circ} \mathrm{C}$ are shown in Fig. 3. It can be seen that PL band for the samples chemically treated before annealing is shifted to shorter wavelengths. The PL intensity in these samples significantly grows, too. It should be noted that the samples being treated after annealing do not demonstrate any noticeable changes in PL spectra. Maximum of PL for samples exposed to ammonia $\left(\mathrm{NH}_{3}\right)$ is about $560 \mathrm{~nm}$. The $\mathrm{PL}$ band for samples exposured to acetone $\left(\mathrm{CH}_{3} \mathrm{COCH}_{3}\right)$ vapour has the peak position near $610 \mathrm{~nm}$.

This essential shift of the maximum and enhancement of the intensity can be caused by two reasons. First, owing to reduced sizes of Si nanocrystals. In paper [14], it is shown that nitrogen can hinder aggregation of crystal nuclei and growth of larger $\mathrm{Si}$ nanocrystals at high-temperature annealing. Therefore, adsorption of the ammonia containing nitrogen, can promote growth of smaller nanocrystals during annealing and a shift of the PL spectrum to the short wave range.

The second reason can be associated with restrictions that are imposed by the oxide matrix. Availability of oxygen causes the formation of silicon-oxygen double bonds at the nc-Si-SiO $\mathrm{x}_{\mathrm{x}}$ interface. Due to these bonds, nc-Si in oxide matrix has localized levels in the band gap and emit light only in the near-infrared range even when the size of nc-Si was controlled to below $2 \mathrm{~nm} \mathrm{[15].} \mathrm{To}$ overcome this restriction, it is possible if using passivation of nc-Si surface by other atoms, for example nitrogen or carbon (that is to change the oxide matrix, at least at nc-Si surface, by another one). In some recent works, short wave radiation (up to $400 \mathrm{~nm}$ ) from nc-Si structures in silicon nitride $[16,17]$ and carbon doped matrix [18] is received.

Our samples have a porous structure and adsorb ammonia or acetone during chemical treatment. In our opinion, the presence of ammonia or acetone in porous oxide layers promotes passivation of nc-Si surface and prevents formation of $\mathrm{Si}=\mathrm{O}$ bonds during annealing in vacuum and further exposure on air. Moreover, the presence of acetyl and methyl effect on oxidation (or oxicarbonization) of silicon and formation of nc-Si with smaller sizes takes place. To make this assumption more obvious, the process of acetone and ammonia exposure needs further investigations. So, chemical treatments of porous $\mathrm{SiO}_{\mathrm{x}}$ films in ammonia and acetone vapour atmosphere with further annealing allow to change shape and intensity of PL band in nc-Si-SiO ${ }_{x}$ structures.

\section{Conclusions}

RF hydrogen plasma treatments of both normally and obliquely deposited nc-Si-SiO $\mathrm{x}_{\mathrm{x}}$ samples allow to increase the PL intensity. But the position of PL peak doesn't change after plasma treatment. Enhancement of the PL intensity in the case of treatment by plasma considerably exceeds influence of the standard hydrogen annealing, because of the plasma treatment not only passivates $\mathrm{Si}$ dangling bonds on the nc-Si-SiO ${ }_{x}$ interface but also anneals structural defects in silicon and its oxide.

As for samples annealed at $700{ }^{\circ} \mathrm{C}$ when amorphous nanoclusters are formed, no changes in PL spectra were observed.

Chemical treatments by ammonia and acetone vapor of porous $\mathrm{SiO}_{\mathrm{x}}$ layers before annealing allow to effect on PL spectra, too. The PL band in these samples is shifted to shorter wavelengths and the intensity of PL significantly grows. The PL peak position for samples exposed to ammonia is about $560 \mathrm{~nm}$, for samples exposed to acetone - near $610 \mathrm{~nm}$. It is assumed that nitrogen in ammonia, and carbon in acetone promotes passivation of nc-Si surface by nitrogen or carbon and prevents formation of $\mathrm{Si}=\mathrm{O}$ bonds.

RF plasma and chemical treatments by ammonia and acetone vapor are efficient methods that allow to increase the PL intensity of silicon nanocrystals embedded in the oxide matrix and vary the PL peak position in a wide spectral range.

\section{References}

1. M. Molinary, H. Rinnert, H. Vergnat, Visible photoluminescence in amorphous $\mathrm{SiO}_{x}$ thin films prepared by silicon evaporation under a molecular oxygen atmosphere // Appl. Phys. Lett. 82, p. 3877 3879 (2003).

2. V.Ya. Bratus', V.A. Yukhymchuk, L.I. Berezhynsky et al., Structural transformations and formation of silicon nanocrystals in $\mathrm{SiO}_{\mathrm{x}}$ films // Semiconductors 35, p. 854-859 (2001).

3. D. Nesheva, C. Raptis, A. Perakis et al., Raman scattering and photoluminescence from $\mathrm{Si}$ nanopaticles in annealed $\mathrm{SiO}_{\mathrm{x}}$ thin films // J. Appl. Phys. 92, p. 4678-4683 (2002)

4. J. Heitmann, F. Müller, M. Zacharias, U. Gösele, Silicon nanocrystals: size matters // Adv. Mater. 17, p. 95-803 (2005).

5. I.Z. Indutnyy, I.Yu. Maidanchuk, V.I. Min'ko, P.E. Shepeliavyi, V.A. Dan'ko, Visible photoluminescence from annealed porous $\mathrm{SiO}_{\mathrm{x}}$ films // $J$. Optoelectron. and Adv. Mater.7, p. 1231-1236 (2005). 
6. Scott R. Kennedy, Michael J. Brett, Porous broadband antireflection coating by glancing angle deposition // Appl. Opt. 42, p. 4573-4579 (2003).

7. A.R. Wilkinson, R.G. Elliman, The effect of annealing environment on the luminescence of silicon nanocrystals in silica // J. Appl. Phys. 96, p. 4018-4020 (2004).

8. B.G. Fernandez, M. Lopez, C. Garcia, et al., Influence of average size and interface passivation on the spectral emission of Si nanocrystals embedded in $\mathrm{SiO}_{\mathrm{x}} / /$ J. Appl. Phys. 91, p. 798-806 (2002).

9. I.P. Lisovsky, I.Z. Indutnyy, B. N. Gnenny et al., Phase-structural transformations in $\mathrm{SiO}_{\mathrm{x}}$ films in the course of vacuum thermal treatment // Semiconductors 37, p. 98-103 (2003).

10. V.S. Lysenko, M.M. Lokshin, A.N. Nazarov, T.E. Rudenko, RF plasma annealing of implanted MIS structures // Phys. status solidi (a) 88, p. 705 712 (1985).

11. V.S. Lysenko, M.M. Lokshin, A.N. Nazarov, T.E. Rudenko, A.S. Tkachenko, Radio-frequency annealing of defects in implanted metal-insulatorsemiconductor structures // Sov. Tech. Phys. Lett. 9, p. 343-344 (1983).

12. I.P. Lisovskyy, I.Z. Indutnyy, V.G. Litovchenko, B.M. Gnennyy, P.M. Lytvyn, D.O. Mazunov, O.S. Oberemok, N.V. Sopinskyy, P.E. Shepeliavyi, Thermostimulated structural transformations in vacuum-evaporated $\mathrm{SiO}_{\mathrm{x}}$ films // Ukrainsky fizychnyi zhurnal (Ukr. Phys. J.) 48, p. 250-255 (2003).

13. M. Nakamura, V. Mochizuki, K. Usami, et al., Infrared absorption spectra and compositions of evaporated silicon oxides $\left(\mathrm{SiO}_{\mathrm{x}}\right)$ // Solid State Communs 50, p. 1079-1081 (1984).

14. Qi Zhang, S.C. Bayliss, D.A. Hutt, Blue photoluminescence and local structure of Si nanostructures embedded into $\mathrm{SiO}_{2}$ matrices // Appl. Phys. Lett. 65 (15), p. 1977-1979 (2003).

15. M.V. Wolkin, J. Jorne, P.M. Fauchet, G. Allan, C. Delerue, Electronic state and luminescence in porous silicon quantum dots: the role of oxygen // Phys Rev. Lett. 82, p. 197 (1999).

16. Tae-Youb Kim, Nae-Man Park, Kyun-Hyun Kim, Gun Yung Sung, Young Woo Ok, Tae-Yeon Seong, Cheol-Jong Choi, Quantum confinement effect of silicon nanocrystals in situ grown in silicon nitride films // Appl. Phys. Lett. 85, p. 5355-5357 (2004).

17. Moon-Seung Yang, Kwan-Sik Cho, Ji-Hong Jhe, SeYoung Seo, Jung H. Shin, Kyung Joong Kim, Dae Won Moon, Effect of nitride passivation on the visible photoluminescence from Si-nanocrystals // Appl. Phys. Lett. 85, p. 3408-3410 (2004).

18. Se-Young Seo, Kwan-Sic Cho, Jung H. Shin, Intense blue-white luminescence from carbon-doped siliconrich silicon oxide // Appl. Phys. Lett. 84, p. 717-719 (2004). 